\title{
A proof-of-principle study of the effect of combined haloperidol and levodopa administration on working memory-related brain activation in humans
}

Citation for published version (APA):

van Ruitenbeek, P., Hernaus, D., \& Mehta, M. A. (2018). A proof-of-principle study of the effect of combined haloperidol and levodopa administration on working memory-related brain activation in humans. Human Psychopharmacology-Clinical and Experimental, 33(5), [e2675]. https://doi.org/10.1002/hup.2675

Document status and date:

Published: 01/09/2018

DOI:

10.1002/hup.2675

Document Version:

Publisher's PDF, also known as Version of record

Document license:

Taverne

Please check the document version of this publication:

- A submitted manuscript is the version of the article upon submission and before peer-review. There can be important differences between the submitted version and the official published version of record.

People interested in the research are advised to contact the author for the final version of the publication, or visit the DOI to the publisher's website.

- The final author version and the galley proof are versions of the publication after peer review.

- The final published version features the final layout of the paper including the volume, issue and page numbers.

Link to publication

\footnotetext{
General rights rights.

- You may freely distribute the URL identifying the publication in the public portal. please follow below link for the End User Agreement:

www.umlib.nl/taverne-license

Take down policy

If you believe that this document breaches copyright please contact us at:

repository@maastrichtuniversity.nl

providing details and we will investigate your claim.
}

Copyright and moral rights for the publications made accessible in the public portal are retained by the authors and/or other copyright owners and it is a condition of accessing publications that users recognise and abide by the legal requirements associated with these

- Users may download and print one copy of any publication from the public portal for the purpose of private study or research.

- You may not further distribute the material or use it for any profit-making activity or commercial gain

If the publication is distributed under the terms of Article 25fa of the Dutch Copyright Act, indicated by the "Taverne" license above, 


\title{
A proof-of-principle study of the effect of combined haloperidol and levodopa administration on working memory- related brain activation in humans
}

\author{
Peter van Ruitenbeek $^{1,2}$ (D) | Dennis Hernaus ${ }^{3}$ | Mitul Ashok Mehta ${ }^{1}$
}

${ }^{1}$ Department of Neuroimaging, Institute of Psychiatry, Psychology and Neuroscience, King's College London, London, UK

${ }^{2}$ Department of Neuropsychology and Psychopharmacology, Faculty of Psychology and Neuroscience, Maastricht University, Maastricht, The Netherlands

${ }^{3}$ Department of Psychiatry; Maryland Psychiatric Research Center, University of Maryland School of Medicine, Baltimore,

Maryland

Correspondence

Peter van Ruitenbeek, Neuropsychology and Psychopharmacology, Faculty of Psychology and Neuroscience, Maastricht University, Universiteitssingel 40, 6229 ER Maastricht, The Netherlands.

Email: p.vanruitenbeek@maastrichtuniversity.nl

\begin{abstract}
Objective: Cognitive deficits including impaired working memory are a hallmark feature of schizophrenia. Dopamine D1 receptor modulated changes in prefrontal cortex function play a potentially important role in the pathology underlying such deficits. However, pharmacological interventions that selectively engage the D1 receptor are severely restricted for research in humans. The present study is a proof-of-principle for enhancing cognitive performance and associated brain activation via indirect D1 stimulation, operationalised by combining the nonselective dopamine agonist L-dopa with the D2-antagonist haloperidol.
\end{abstract}

Methods: Fourteen healthy volunteers received placebo or combined carbidopa $(25 \mathrm{mg}) / \mathrm{L}$-dopa $(100 \mathrm{mg})$ plus haloperidol $(2 \mathrm{mg}$ ) orally on two separate occasions according to a within-subjects crossover design. Drug-induced differences in brain activity were assessed during an $\mathrm{N}$-back working memory task in a $3 \mathrm{~T}$ magnetic resonance imaging environment.

Results: Drug treatment was associated with greater functional connectivity between the dorsolateral prefrontal cortex and areas within the salience network during all $\mathrm{N}$-back trials. Drug treatment was also associated with reduced activation, most prominently in the occipital/temporal brain areas during 2-back performance.

Conclusions: This preliminary study provides initial evidence for combined L-dopa/ haloperidol modulation in cognition-related brain areas and networks, which is relevant for the treatment of cognitive impairments in mental illness.

\section{KEYWORDS}

D1 receptor, dopamine, haloperidol, levodopa, schizophrenia, working memory

\section{1 | INTRODUCTION}

Schizophrenia is characterised by broad and persistent cognitive deficits, including impaired working memory and episodic memory, executive functioning and attention (Fioravanti, Bianchi, \& Cinti, 2012). Although currently available pharmacological treatments are primarily aimed at decreasing positive symptoms (e.g., hallucinations), they do not alleviate cognitive deficits (Marder, 2006). Cognition-

Abbreviations: BA, Brodmann areas; DLPFC, dorsolateral prefrontal cortex; FWE, family-wise error rate; GLM, general linear model; gPPI, generalised psychophysiological interactions; HAL/DOP, haloperidol/L-dopa treatment; MNI, Montreal Neurological Institute; PFC, prefrontal cortex; PLC, placebo; SNR, signal-to-noise ratio; TO, time of treatment; T60, 60 min post-treatment; T120, 120 min post-treatment; T150, 150 min post-treatment; T210, 210 min posttreatment; TFCE, threshold free cluster enhancement; TP, time point 
enhancing agents for schizophrenia represent a core unmet need: In addition to direct treatment of cognitive deficits, these agents may promote functional independence via improved insights into disease and therapy (Green, Kern, Braff, \& Mintz, 2000). Here, we aim to provide proof-of-principle evidence for a potential cognitionenhancing treatment, which could inform a novel treatment strategy for individuals with schizophrenia (Saha, Chant, \& McGrath, 2007).

Dopamine D2 receptor antagonists are the most widely used class of pharmacological agents in schizophrenia. It is thought that D2 receptor blockade, primarily in striatum, is the main mechanism of action by which antipsychotics decrease positive symptoms. Importantly, however, D2 receptor blockade does not appear to explain the modest improvement in cognitive impairments seen in some patients (Goldberg et al., 2007) and treatment with second-generation antipsychotics does not improve working memory and attentional functions (Nielsen et al., 2015), underlining the need for alternative approaches.

Preclinical research has established that dopamine D1 receptors essentially modulate prefrontal cortex (PFC)-mediated working memory (Sawaguchi \& Goldman-Rakic, 1991). For example, D1 agonism improves working memory in aged monkeys (Castner \& Goldman-Rakic, 2004), whereas D1 antagonism negatively impacts spatial working memory abilities. At the neural level, D1 receptor activity increases signal-to-noise ratio (SNR) in neural networks, including PFC, most likely by decreasing spontaneous firing of neurons (Seamans, Gorelova, Durstewitz, \& Yang, 2001). An optimal level of PFC dopamine activity has been described by many studies in experimental animals and humans, with insufficient and excessive D1 receptor activation leading to reduced SNR (Akaike, Ohno, Sasa, \& Takaori, 1987), and an inverted-U shaped relationship between dopamine activity and cognitive performance (Cools \& D'Esposito, 2011).

Cognitive deficits in schizophrenia may be the consequence of altered dopamine D1, rather than D2, function in PFC (Abi-Dargham et al., 2002). This notion is supported by the observation that D1 receptor density in PFC correlates with cognitive performance in schizophrenia (Abi-Dargham, 2003) and schizotypal personality disorder (Thompson et al., 2014). Moreover, in animal models of schizophrenia, D1 receptor agonism can reverse cognitive impairments (McLean, Idris, Woolley, \& Neill, 2009). In light of this evidence, D1 receptors have long been considered potential treatment targets (Goldman-Rakic, Castner, Svensson, Siever, \& Williams, 2004).

Dopamine D1 receptors can be stimulated directly or indirectly, although currently available compounds have significant drawbacks (Arnsten, Girgis, Gray, \& Mailman, 2016). For example, amphetamine nonselectively enhances catecholaminergic and serotonergic activity, in addition to its abuse potential. The D1 receptor agonist SFK38393 is potentially useful, as it reverses phencyclidine-induced cognitive deficits in experimental animals, but it has not been used in humans (McLean et al., 2009). DAR-0100A is the only selective D1 receptor agonist available for use in humans. There are preliminary findings suggesting improved spatial working memory in schizotypal personality disorder (Rosell et al., 2015) and enhanced perfusion of prefrontal and nonprefrontal brain areas in schizophrenia patients (Mu et al., 2007). However, DAR-0100A did not improve executive functions or cognition-related brain function in schizophrenia (Girgis et al., 2016), it has exclusively been used at doses that do not produce measurable D1 receptor occupancy (Slifstein et al., 2011) and produces a range of side effects (George et al., 2007). In addition, the agent's short half-life (Blanchet et al., 1998) complicates successful treatment.

An alternative and accessible approach is to increase dopamine turnover nonselectively and simultaneously block D2 receptors, hypothetically producing dopamine D1 receptor agonism. Dopamine turnover can be increased nonselectively by administration of its precursor L-dopa, which increases dopamine synthesis in the central nervous system and periphery (Rosen, Flemenbaum, \& Slater, 1986). Peripheral increases in dopamine can be blocked by carbidopa, further increasing central dopamine availability (Rosen et al., 1986). Haloperidol has a mixed profile but acts principally as a dopamine D2-antagonist.

In the present proof-of-principle study, we hypothesised that simultaneous administration of L-dopa/carbidopa and haloperidol would decrease PFC brain activity and increase functional connectivity (Meyer-Lindenberg et al., 2001) during a working memory paradigm, possibly as a consequence of increased D1 activation. Here, drug-induced decreases in brain activity in combination with functional connectivity increases indicate more efficient network activity, the result of increased SNR (Callicott et al., 2000). As drug-induced performance increases may be difficult to establish in healthy volunteers, who already function at a near-optimal level, we relied on the sensitive nature of BOLD fMRI during N-back task performance. The N-back is a well-established paradigm for probing working memory function has been used extensively in schizophrenia (e.g., Bertolino et al., 2003) and is sensitive to dopaminergic drug effects (Mattay et al., 2000).

\section{2 | METHODS}

\section{1 | Participants}

We recruited 14 healthy right-handed male volunteers aged between 19 and 38 years (mean $\pm S D=25.0 \pm 5.1$ years) by circular email sent to students and staff from King's College London who were financially compensated for their time. Using BOLD for the dorsolateral PFC (DLPFC) from in-house N-back data set, we estimated that with 14 participants we have a power of $\sim 0.55$ to detect a $50 \%$ reduction in BOLD signal amplitude in the drug condition at $p<0.05$. Inferences were planned for cluster correction statistics for which a priori power analyses is difficult. Participants' physical and mental status were assessed by a screening involving a urine analysis and test for the presence of drugs of abuse (amphetamines, methamphetamines, THC, methadone, opiates, phencyclidine, barbiturates, benzodiazepine, and tricyclic antidepressants), a 12-lead electrocardiogram, measurements of heart rate and blood pressure, breath alcohol concentration and blood chemistry and haematology.

Volunteers were excluded if they showed any evidence or history of clinically significant renal, pulmonary, gastrointestinal, cardiovascular, hepatic, psychiatric, or neurological disease/disorder, including epilepsy or seizures and more than one febrile convulsion. In addition, volunteers were excluded from the study if they used any prescribed 
or nonprescribed drugs except paracetamol and acetaminophen, drank more than 28 standard alcohol units per week, smoked more than five cigarettes per day, were treated with a new chemical entity within the past 3 months, had a known sensitivity to any of the study medications, a Body Mass Index outside the limits of $18-30 \mathrm{~kg} \cdot \mathrm{m}^{-2}$, nonremovable metallic items in/on their body or signs of claustrophobia.

All participants gave written informed consent before they entered the study that was approved by the King's College Research Ethics Committee (RECnr.: 10/H0807/13) and was conducted in accordance with the World Medical Association Declaration of Helsinki and its amendments (World-Medical-Association, 1964, 1996, 2008, 2013).

\section{2 | Experimental design and treatment}

The study was carried out according to a two-way double blind, placebo-controlled design. Study medications were combined oral doses of haloperidol $2 \mathrm{mg}$ and L-dopa $100 \mathrm{mg} /$ carbidopa $25 \mathrm{mg}$ or placebo (ascorbic acid) administered according to a double dummy procedure. Administration order was randomised and counterbalanced across participants. Haloperidol $2 \mathrm{mg}$ was chosen because it has been shown to block $60-75 \%$ of D2 receptors and doses up to $3 \mathrm{mg}$ are generally well tolerated according to the literature (Legangneux et al., 2000) and our own experience (Handley et al., 2013; Hawkins et al., 2018). L-dopa $100 \mathrm{mg} /$ carbidopa $25 \mathrm{mg}$ was chosen because it is also well tolerated and produces minimal side effects in healthy volunteers (Floel et al., 2008; Symmonds, Wright, Fagan, \& Dolan, 2013). In addition, the dose of levodopa has been used in numerous previous studies in healthy volunteers, a dose that usually produces cognitive effects (Breitenstein et al., 2006; Knecht et al., 2004; Symmonds et al., 2013; Wittmann \& D'Esposito, 2015). At these doses, we expected side effects to be well tolerated, adding to protecting the blind. However, nausea occasionally occurs, which we aimed to prevent by administration of peripherally acting dopamine antagonist domperidone that was administered prior to the start of the experiment on both study days (drug and placebo).

\section{3 | Procedure}

The volunteers visited the Centre for Neuroimaging Sciences three times. The first visit was a screening/training visit during which volunteers gave their written informed consent, were medically screened, and performed the tasks in a mock scanner to familiarise them with the MRI environment and task procedures. The second and third visits were scanning visits. After confirming suitability (including a physical assessment conducted by a physician), subjective mood was assessed using 16 visual analogue scales (Bond \& Lader, 1974). Volunteers received haloperidol $2 \mathrm{mg}$ and domperidone or placebo at time TO. After waiting for $60 \mathrm{~min}$, they received L-dopa $100 \mathrm{mg} /$ carbidopa $25 \mathrm{mg}$ or placebo (T60), ensuring that plasma peak levels of both drugs occurred at similar times $\left(\mathrm{T}_{\max }\right.$ Haloperidol $=1.7-6.1 \mathrm{hr}$ [Kudo \& Ishizaki, 1999], $\mathrm{T}_{\max } \mathrm{L}$-dopa $=15-60 \mathrm{~min}$ [Contin \& Martinelli, 2010]); $120 \mathrm{~min}$ after the administration of the first dose (T120) a second assessment of subjective mood was performed using the visual analogue scales. Volunteers received a small standardised lunch and entered the scanner 150 min after the first dose (T150). Visual stimuli were back-projected on a screen, which the volunteer could see using periscopic mirrors. After scanning, volunteers' subjective mood was assessed again. Finally, a physical examination was performed as part of a discharge assessment by the physician.

\section{4 | Materials and tests}

\subsection{1 | N-back task}

The N-back task is a well-established working memory task that reliably activates the DLPFC (Owen, McMillan, Laird, \& Bullmore, 2005) and has been used in many studies to assess drug-induced changes in working memory performance The current version of the task consisted of four conditions: 1-back, 2-back, 3-back, and a 0-back control condition. Each task condition occurred three times as blocks of 14 letters sequentially presented on a screen for $2 \mathrm{~s}$ per letter. Before each 28-s block of trials, the upcoming condition was briefly presented for $2 \mathrm{~s}$. Volunteers responded to cues with a button press on a response box using their right index (target) and left index (nontarget) finger. A target stimulus was defined as a letter that matched the previous one in the 1-back condition (e.g., "A" followed by "A"), a letter presented two letters earlier in the 2-back condition (e.g., "A," "B," and " $A$ "), a letter presented three letters earlier in the 3-back condition (e.g., "A," "B," "C," and "A") or was an X in the 0-back condition (e.g., "A," "B," and "X"). The total length of the task was 6 min and $20 \mathrm{~s}$. Reaction time and responses were recorded, and average reaction time and number of correct responses were dependent variables.

\subsection{2 | Subjective mood ratings}

Subjective evaluations of alertness, contentedness, and calmness were assessed using a series of 16 visual analogue scales (100 mm), which provided factor analytically defined summary scores for "alertness," "contentedness," and "calmness" (Bond \& Lader, 1974). Participants were asked to indicate their current mood state by marking a horizontal line in between two extremes of a given mood dimension, for example, alert-drowsy.

\section{5 | Image acquisition}

All MRI data were collected at the Centre for Neuroimaging Sciences, King's College London using a General Electric 3 Tesla Signa HDx scanner (General Electric, Milwaukee) with an eight channel head coil. Volunteers lay in a supine head first position in the scanner. One hundred and eighty-six T2*-weighted images were acquired during $\mathrm{N}$-back task performance using a gradient echo planar imaging sequence with repetition time/echo time $=2000 / 30 \mathrm{~ms}$, flip angle $=75^{\circ}, 37$ slices (sequential, top-bottom), slice thickness $/$ gap $=3$ / $0.3 \mathrm{~mm}$, in-plane resolution $3.3 \mathrm{~mm}^{2}$, and field of view $21.1 \mathrm{~cm}$. To allow for accurate normalisation to a standard space, a whole-brain three-dimensional inversion recovery prepared spoiled gradient echo scan was also collected with isotropic 1.1-mm voxels in a scan time of approximately $6 \mathrm{~min}$ (repetition time/echo time 6.96/2.82 ms; inversion time $=450 \mathrm{~ms}$; excitation flip angle $=20^{\circ}$ ). 


\section{6 | Image preprocessing}

Imaging data were processed in SPM8 (http://www.fil.ion.ucl.ac.uk/ spm/) using Matlab (V7.0.1.; https://mathworks.com) on a UNIX platform. Slices were corrected for acquisition time using the middle slice as reference. The data were corrected for translational and rotational movement in three dimensions, first by registering all images to the first in the series and then to the mean image. In all runs, volunteer head movement did not exceed the limit of one voxel on no more than three occasions within one run, either translational or rotational (i.e., rotational limit equating to one voxel at the brain surface). The functional data were coregistered with the high resolution T1-weighted image data using the mean image to determine the parameters. The T1-weighted images were normalised to standard $\mathrm{MNI}$ space using unified segmentation with the parameters applied to the functional time series which were then smoothed using a Gaussian kernel of $8 \mathrm{~mm}$ of full width at half maximum. All scans were visually inspected for quality of preprocessing.

\section{7 | Data and statistical analysis}

\subsection{1 | Behavioural data}

Two participants did not perform above chance level on 2-back and 3back trials, and their data were excluded from analysis. For the remaining 12 participants, a $2 \times 4$ general linear model for repeated measures analyses were performed for reaction time and correct responses, with treatment (two levels: haloperidol/L-dopa and placebo) and level of difficulty (four levels: 0-, 1-, 2-, and 3-back) as within subject factors. We tested for a main effect of treatment and level of difficulty and their interaction at $\alpha=0.05$ significance level, corrected using Greenhouse-Geisser method when the sphericity assumption was violated. A significant main effect of level of difficulty was further specified using contrasts between 0-back condition and 1-, 2-, and 3-back condition. A significant interaction between level of difficulty and treatment was further specified using drug-placebo contrasts within each difficulty level.

Visual analogue scales data from all 14 participants were analysed separately for three factors (alertness, contentedness, and calmness) using general linear model for repeated measures with treatment (two levels: haloperidol/L-dopa and placebo), and time point (three levels: T0, T120, and T210) as within-subjects factors. Significance level was set at $\alpha=0.05$ and was corrected using Greenhouse-Geisser when the sphericity assumption was violated. All behavioural data were analysed using SPSS 18 (SPSS inc., 2009).

\subsection{2 | Imaging data}

For 12 participants performing above chance level, functional images were first analysed at the single-subject level in the framework of the general linear model. The design matrix comprised 11 regressors; 0-, 1-, 2-, and 3-back trial blocks, visually presented instructions, and three translational and three rotational movement parameters, for which Beta weights were estimated. Next, contrasts were defined between 0-back and 1-, 2-, and 3-back, representing activation during 0-back subtracted from activation during the other $\mathrm{N}$-back difficulty levels. For the 2 nd level analysis, all first level contrasts were resliced to match the FMRIB Software Library's (FSL; [Jenkinson, Beckmann, Behrens, Woolrich, \& Smith, 2012]) MNI152 2 mm template. Next, all contrasts images were concatenated into a single four-dimensional file. Using FSL's randomise (Winkler, Ridgway, Webster, Smith, \& Nichols, 2014) F-contrasts for treatment (two levels: haloperidol/L-dopa and placebo) and level of difficulty (three levels: 1-, 2-, and 3-back > 0-back contrasts), and their interaction were calculated in a model with treatment and level of difficulty as fixed factors and subject as random factor. Significant (TFCE, $p<0.05$ FWE corrected) main effects or interaction were further analysed using t-contrasts.

In addition, generalised psychophysiological interaction (gPPI; McLaren, Ries, Xu, \& Johnson, 2012) analysis was performed to determine if combined haloperidol/L-dopa treatment affected task-dependent correlations between brain areas within the network activated during $\mathrm{N}$-back task performance. First, the DLPFC was chosen a priori as seed region given its prominent role in $\mathrm{N}$-back performance (Owen et al., 2005) and its involvement in schizophrenia working memory pathology (Abi-Dargham et al., 2002). The region was identified in the current data set by performing an $F$ test for the main effect of level of difficulty taken from the analysis described above. Peak MNI coordinates from this analysis in the current data set (i.e., right DLPFC: $44,26,36$ ) were used to guide the identification of active brain areas in all of the runs separately, locating the nearest local maximum. Subsequently, a 6-mm sphere was created around the peak voxel that was masked with the activation map from the $F$ test for level of difficulty resulting in a volume of interest containing only active voxels per run. The volume of interests were fed into the gPPi analysis using the SPM toolbox provided by McLaren et al. (2012; http://www.nitrc. org/projects/gppi). gPPI has the advantage over PPI that it accommodates multiple task conditions, that may explain variance of the dependent variable, and provides a better model fit (McLaren et al., 2012). Using the gPPi toolbox, contrast images are created representing memory load dependent activation correlated with activation of the seed region (PPI term). A 2nd level analysis was performed to determine treatment differences in PPI terms: that is, differential effects of haloperidol/L-dopa and placebo on memory load-dependent DLPFC functional connectivity. Using permutation testing with FSL's randomise, the F-contrasts for main effect of treatment was calculated within the $\mathrm{N}$-back network. To explore the direction of findings from the $F$ test, $t$-contrasts were calculated using TFCE and a $p<0.05$, FWE corrected.

Finally, B estimates for cluster peak voxels were extracted and correlated with a dose to body weight ratio $\left(\mathrm{mg} \cdot \mathrm{kg}^{-1}\right)$ for both haloperidol and L-dopa.

\section{3 | RESULTS}

\section{1 | Behavioural data}

\subsection{1 | N-back task}

Increased level of difficulty was accompanied by a significantly lower percentage of correct responses and significantly increased the average reaction time. Compared with the 0-back condition, responses were significantly slower during 1-back blocks, and 
significantly fewer correct- and slower responses were given during 2-back blocks and 3-back blocks.

The combination of haloperidol and L-dopa did not significantly affect the percentage of correct responses or the average reaction time on any level of difficulty or across levels of difficulty. However, a trend for more correct responses after haloperidol and L-dopa was observed for 0-back ( $\left.t_{11}=-1.865, p<0.089\right)$ and 1-back $\left(t_{11}=-1.820, p<0.096\right)$ task conditions, in absence of a significant increase in reaction time. Please see Figure 1 and Table 1 for descriptive and significance statistics.

\subsection{2 | Subjective mood ratings}

Time point showed a significant effect on measures of alertness and contentedness. Alertness significantly decreased over time points and contentedness was lower at T120 compared with TO and with T210. Drug treatment did not affect subjective ratings of alertness or contentedness. The treatment by time point interaction showed a trend, driven by haloperidol/L-dopa increasing calmness over time compared with placebo. Contrasts between haloperidol/L-dopa and placebo were significant or close to significance for differences between calmness measured at T210 and T0, and T210 and T120.

\section{2 | Imaging data}

\subsection{1 | N-back: Level of difficulty effects}

F-contrast for the main effect of Level of difficulty indicating any activation differences with 0 -back resulted in a large number of significant clusters of activation (see Figure 2). In addition, t-contrasts assessing where brain activity increased with task difficulty revealed a number of significant areas in the 2-back > 1-back contrast, which closely resembled the activation pattern of the general F-contrast. In addition, the 3-back > 2-back t-contrast did not reveal any significant activity differences.

\subsection{2 | N-back: Treatment effect}

An F-contrast for treatment effects indicated significant activation differences between drug and placebo sessions. T-contrasts revealed that combined haloperidol/L-dopa administration significantly decreased brain activation in a wide range of regions compared with placebo (see Figure 3 and Table 2).

Although no significant treatment by level of difficulty interaction was observed, planned t-contrasts did reveal a significant treatment effect during the 2-back condition. During the 2-back condition, combined haloperidol/L-dopa administration reduced activity in a large number of clusters that mostly overlapped with the clusters from the overall F-contrast for treatment. A noticeable exception was reduced activation in bilateral caudate, right amygdala, and right thalamus (see Figure 3 and Table 3).

\subsection{3 | N-back connectivity}

Planned exploratory $t$ tests showed that combined haloperidol/L-dopa treatment increased task-dependent connectivity between DLPFC and several clusters for all N-back contrasts (1-, 2-, and 3-back vs. 0-back). The first cluster included right superior frontal gyrus (peak voxel at BA8), bilateral paracingulate gyrus (peak voxel at BA32), and right middle frontal gyrus (peak voxel at BA45). The second cluster included two peaks in the right premotor cortex (peak voxels at BA6). Finally, one cluster was detected in the left premotor cortex (peak voxel at BA6). Please see Figure 4 and Table 4 for details. None of the correlations between cluster peak voxel beta weights and the drug-body weight ratio were significant.

\section{4 | DISCUSSION}

Here, we provide preliminary data for the effects of combined haloperidol/L-dopa administration on working memory-related brain activation. It was hypothesised that the combined haloperidol/L-dopa administration would induce changes in brain activity associated with $\mathrm{N}$-back task performance, potentially by increasing SNR. In line with this hypothesis, smaller drug-induced differences in activity for the 2-back versus 0-back contrast were observed in a large number of brain areas, most notably in the occipital/temporal cortex. Further, we observed drug-induced accentuated connectivity between DLPFC and right frontal brain areas (superior and middle frontal gyrus and paracingulate gyrus) as well as sensorimotor areas (bilateral premotor cortices).

\section{Reaction time}

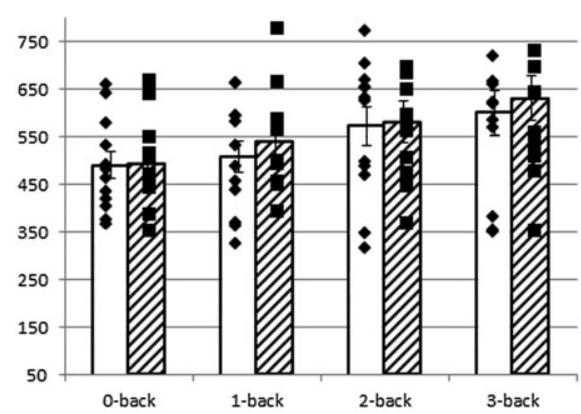

\section{Percentage correct}

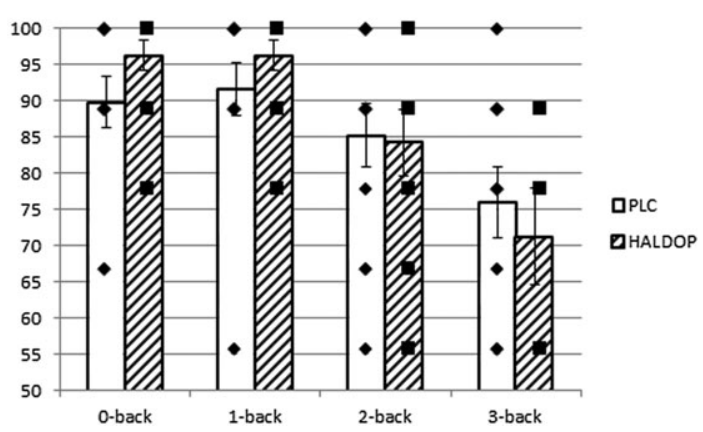

FIGURE 1 Performance on different levels of N-back task difficulty after receiving placebo or a combination of L-dopa and haloperidol according to a within-subjects design $(n=12)$. No significant drug effects were observed, although drug treatment was followed by more accurate responses during 0-back and 1-back at a trend level $(p<0.1)$. HAL/DOP: haloperidol/L-dopa treatment; PLC: placebo 
TABLE 1 Descriptive statistics and test of significance of reaction times and percentage of correct answers for the four levels of difficulty of the $\mathrm{N}$-back task performed after a single dose of placebo or haloperidol/L-dopa/carbidopa drug treatment

\begin{tabular}{|c|c|c|c|c|c|c|c|}
\hline & Mean & SEM & Mean & SEM & $F=$ & $d f$ & $p<$ \\
\hline \multirow[t]{2}{*}{ RT (ms) } & & & & & 10.059 & 3,9 & $0.003^{*}$ \\
\hline & Placebo & & Haloperidol & idopa & 0.271 & 1,11 & n.s. \\
\hline 0-back & 490.0 & 90.4 & 492.4 & 100.6 & -0.101 & 11 & n.s. \\
\hline 1-back & 508.9 & 122.9 & 541.8 & 112.6 & -1.493 & 11 & n.s. \\
\hline \multirow[t]{3}{*}{ Correct (\%) } & & & & & 5.612 & 3,9 & $0.019^{*}$ \\
\hline & Placebo & & Haloperidol & idopa & 0.733 & 1,11 & n.s. \\
\hline & & & & & $t=$ & $d f$ & $p<$ \\
\hline 0-back & 89.8 & 3.5 & 96.3 & 2.1 & -1.865 & 11 & n.s. \\
\hline
\end{tabular}

Note. Performance on both measures was significantly affected by level of difficulty. Drug treatment did not significantly affect either measure. $d f$ : degrees of freedom; n.s.: not significant; RT: reaction time; SEM: standard error of measurement.

${ }^{*} p<0.05$.

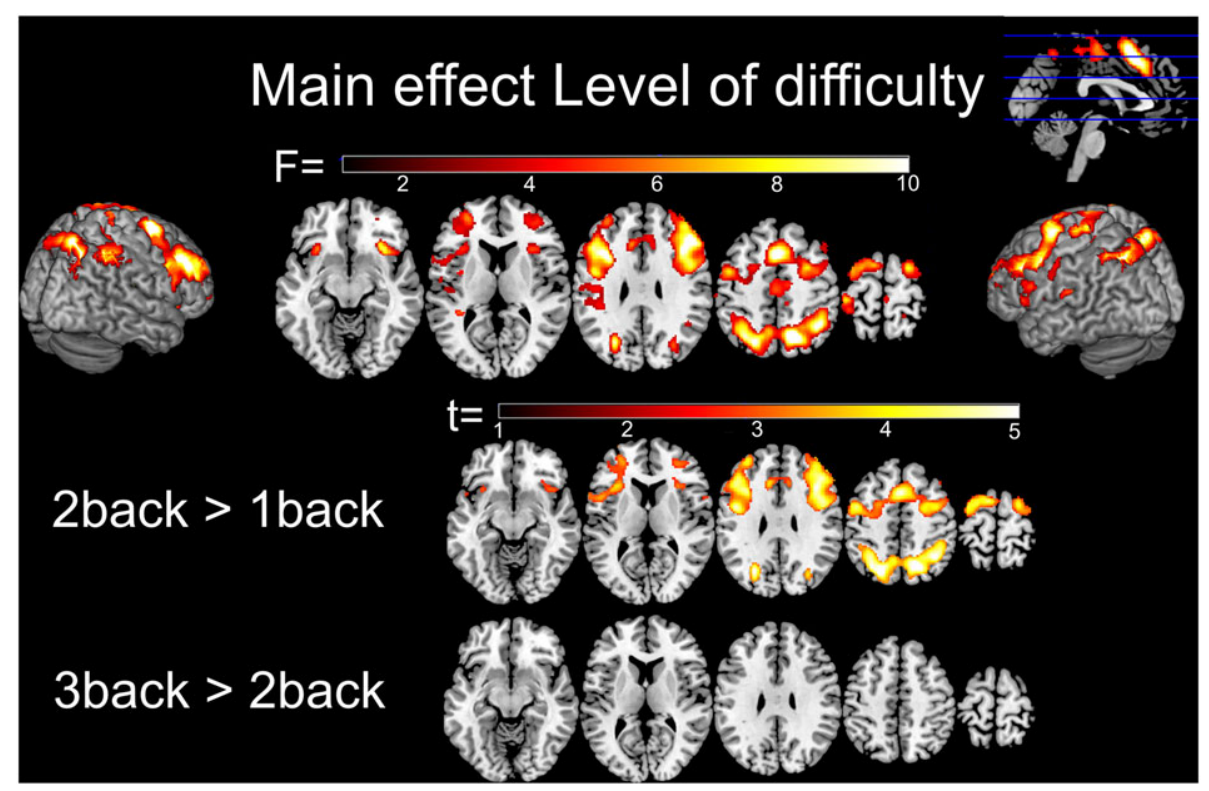

FIGURE 2 Main effects of Level of difficulty (within subject variable, $n=12$ ) on brain activation and contrasts between 1-back and 2-back and between 2-back and 3-back. Results indicate that the 2-back condition evoked network activation most robustly in premotor cortex (BA6), supplementary motor area (BA6), anterior cingulate (BA32), superior parietal lobule (BA7), inferior parietal lobule (BA40), Broca's area (BA44, 45), middle frontal gyrus (BA46), insula (BA47, 48), and frontal pole (BA10)

Specifically, the current results show increased functional connectivity of the DLPFC for all N-back versus 0-back conditions after haloperidol/L-dopa treatment compared with placebo. For the present discussion, it must be stressed that the aim is to consider the combined haloperidol/L-dopa treatment to increase dopamine functioning and not to tease apart the effects of either drugs. Within this context, our observations are in line with an accumulating body of evidence that suggests that dopamine agonism increases the strength of PFC-mediated networks that essentially underlie higher order functions. For example, enhanced network integration during $\mathrm{N}$-back performance was also observed after administration of the noradrenaline transporter inhibitor atomoxetine, which increases prefrontal catecholamine levels (Shine, van den Brink, Hernaus, Nieuwenhuis, \& Poldrack, 2017). Atomoxetine also enhances DLPFC activity during a response inhibition paradigm (Chamberlain et al., 2009), enhances DLPFC functional connectivity during a working memory paradigm (Hernaus, Casales Santa, Offermann, \& Van Amelsvoort, 2017), and increases functional connectivity strength in occipital areas (van den Brink et al., 2016). Importantly, D1 antagonism decreases effective connectivity between DLPFC and brain regions associated with load- 


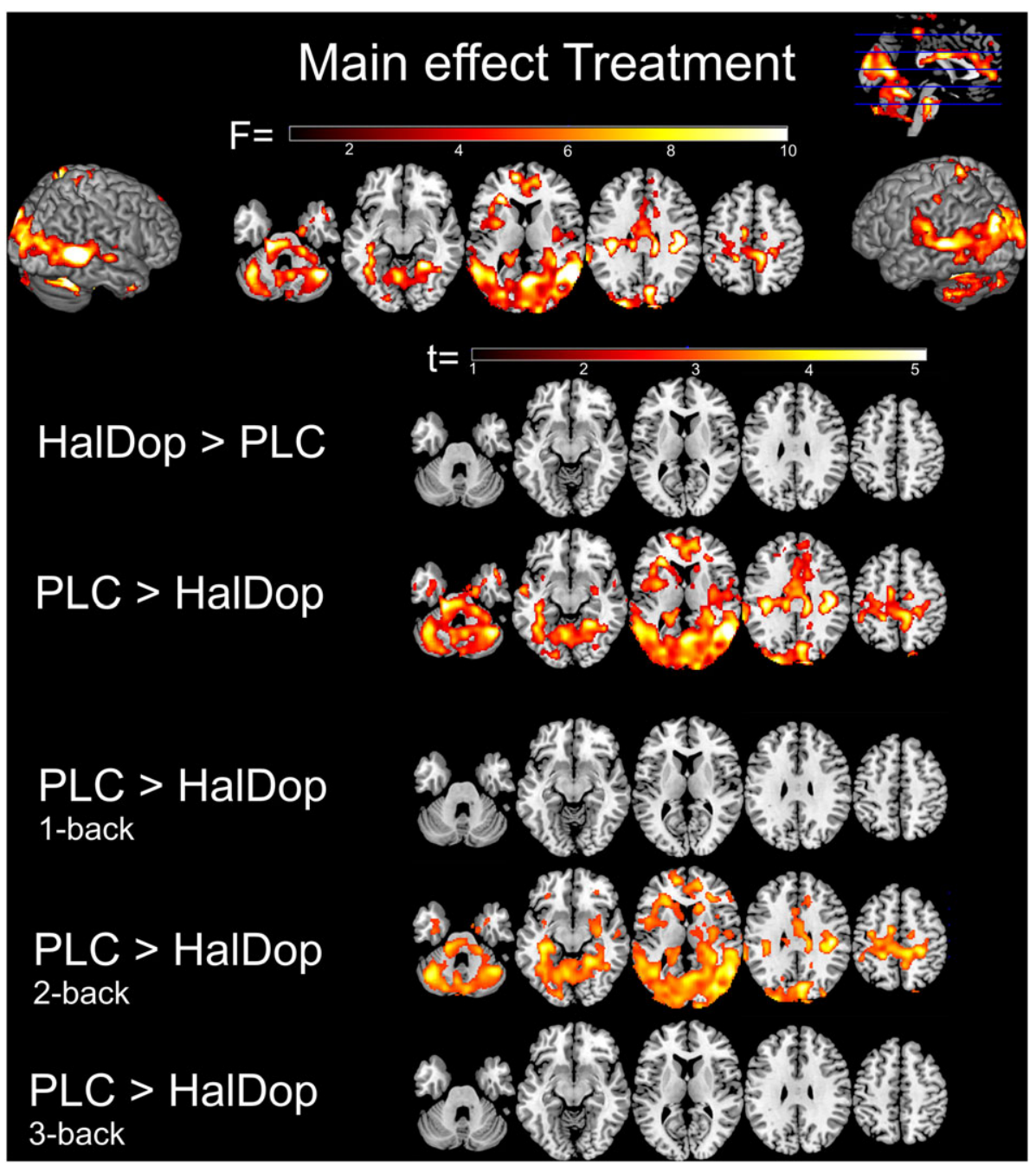

FIGURE 3 A main effect of Treatment (within subject variable, $n=12$ ) on brain activation during $N$-back performance was observed in a large number of brain areas. Specific t-contrasts indicate that brain activation decreased after drug treatment, specifically during the 2-back task condition. HAL/DOP: haloperidol/L-dopa treatment; PLC: placebo

dependent working memory performance (Rieckmann, Karlsson, Fischer, \& Backman, 2012), many of which were also observed in the present study (e.g., paracingulate and premotor cortex). Moreover, L-dopa enhanced memory load-dependent working memory performance that coincided with increased frontal low theta power (Eckart, Fuentemilla, Bauch, \& Bunzeck, 2014). In contrast, D2 blockade has been shown to decrease cortico-striatal connectivity in humans (Cole et al., 2013) and rats (Gass et al., 2013) at rest and decreases frontal cortical activity during tasks of response inhibition (Luijten et al., 2013) and working memory (Goozee et al., 2016). Finally, D2 agonism mostly results in increased activation in memory-related networks (Dumas, Filippi, Newhouse, \& Naylor, 2017; Gibbs \& D'Esposito, 2005a, but see Kimberg, Aguirre, Lease, \& D'Esposito, 2001, for an exception). Thus, similarities between our observation of drug-induced increase in connectivity within $\mathrm{N}$-back network and other studies of (nonselective) dopamine agonism favour the interpretation that a combination of haloperidol and L-dopa may lead to D1-dependent accentuation of PFC-mediated network integrity.

The drug-induced effects on occipital/temporal cortex activation were unexpected as these areas are not part of the typical task networks. Working memory-related activity in fronto-parietal regions during the placebo session aligned well with expectations from a meta-analysis of N-back studies (Owen et al., 2005) and did not include occipital/temporal cortex. Currently, observed activity decreases in Brodmann areas 18 and 19 are part of the extrastriate cortex and are generally involved in processing of lower level visual information, such as motion, colour, and contrast (Grill-Spector \& Malach, 2004), while working memory-related activity changes in these regions are not typically observed during the $\mathrm{N}$-back task. The results are also unlikely to be explained by simple changes in visual processing time as no reaction times differences were observed. However, drug-induced changes outside of the typical task network have been observed previously. Furey, Pietrini, Alexander, Schapiro, and Horwitz (2000) showed that cholinergic enhancement can increase extrastriate cortex activation during encoding, which was accompanied by better working memory performance and reduced requirements for prefrontal activity. Therefore, even though the extrastriate cortex is not typically involved in specific working memory processes, drug-induced modulation of its activation can coincide with changes in performance. 
TABLE 2 Brain areas and peak cluster voxels showing less activation following haloperidol/L-dopa compared with placebo over all N-back conditions

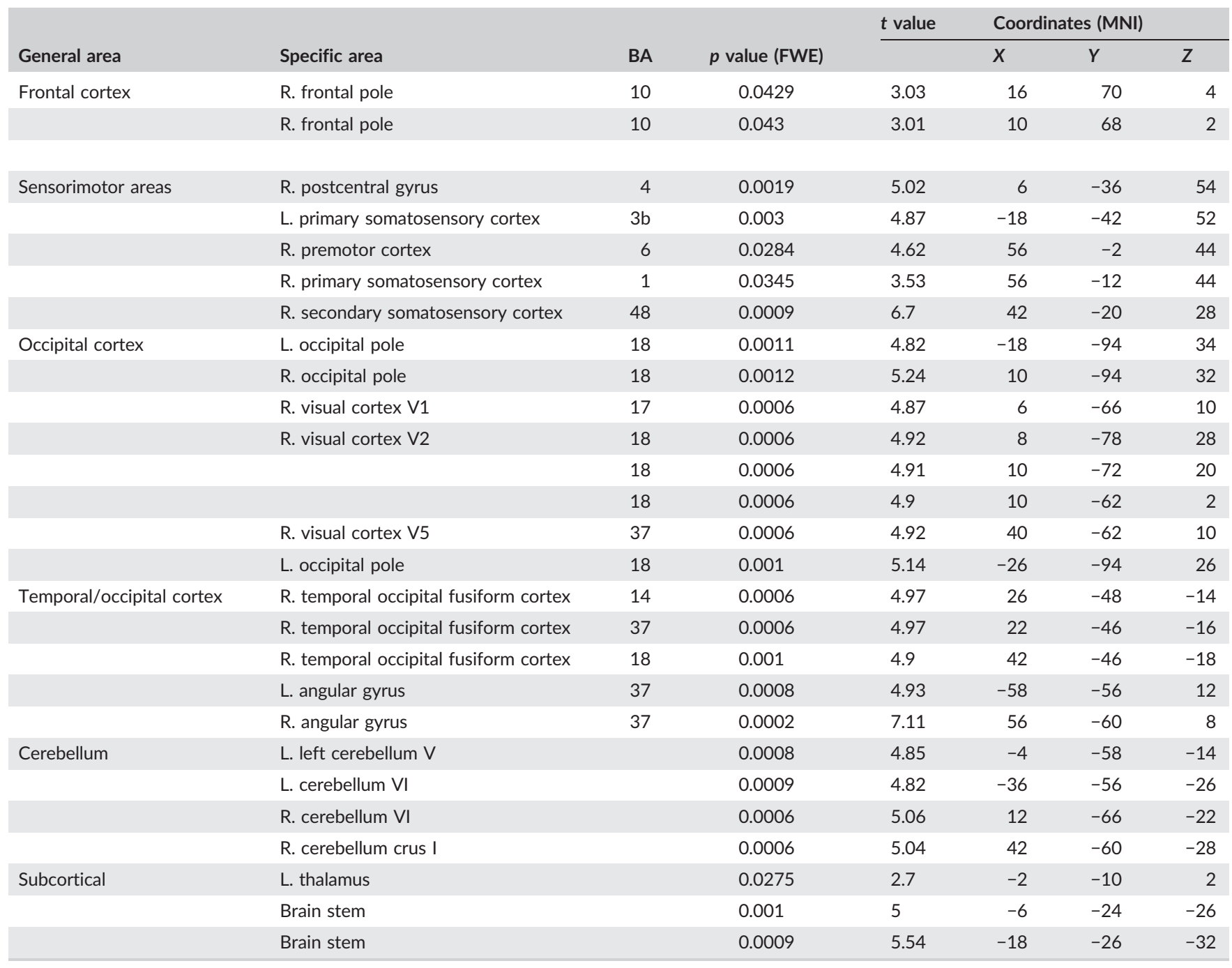

Note. The $t$ values, $p$ values, and MNI coordinates indicate peak voxels within the clusters. BA: Brodmann area; FWE: family-wise error rate; MNI: Montreal Neurological Institute.

Despite that the present study is not designed to explore the separate drug effects, some similarities between the presently observed activation patterns and results from other studies manipulating dopamine may be considered. The presently observed decrease in occipital/temporal cortex activation may be speculated to be a direct consequence of local D1 or D2 receptor modulation or indirect action via other regions (Yoon, Curtis, \& D'Esposito, 2006). Considering direct action, the presence of dopamine D1 and D2 receptors in this region is low compared with other cortical areas (Abi-Dargham et al., 2000; www.brain-map.org), potentially limiting direct local effects. Importantly, functional imaging shows that dopaminergic modulation with L-dopa does not alter $\mathrm{rCBF}$ measured with positron emission tomography in the posterior occipital/inferior temporal areas (Hershey et al., 2003) and haloperidol reduced relative, but not absolute, blood flow in the posterior inferior temporal lobe in healthy volunteers given a single dose of $3 \mathrm{mg}$ (Handley et al., 2013). However, activity changes only occurred during the 2-back condition and are thus unlikely to be explained by changes in blood flow, which would be expected to impact all conditions. In contrast, current evidence favours an indirect D2-receptor mediated decrease in task-related activation. Brassen et al. (2003) observed a decrease in visual stimulation-evoked BOLD response in similar visual areas (BA18/19) after intravenously administered haloperidol. Gibbs and D'Esposito (2005b) and Vytlacil, Gibbs, Chen, and D'Esposito (2009) observed modulation of the visual association cortex activity in a working memory task after administration of the D2-agonist bromocriptine. Taken together, there is some evidence that D2 receptors modulate working memory-related occipital cortex activation, and those effects are likely to be the result of altered activation of regions connected to the occipital cortex. However, the present study was not designed to provide direct evidence for the effects of haloperidol. Therefore, this conclusion should be considered with caution.

As no significant effects on performance were observed, the behavioural consequences of combined haloperidol and L-dopa administration remain unclear. Despite the small sample size, the nonsignificance of the drug-induced effects is in line with previous results suggesting that haloperidol $2 \mathrm{mg}$ only has minor effects on 
TABLE 3 Brain areas and peak voxels in which haloperidol/L-dopa produces less activation compared with placebo during the 2-back condition

\begin{tabular}{|c|c|c|c|c|c|c|c|}
\hline \multirow[b]{2}{*}{ General area } & \multirow[b]{2}{*}{ Specific area } & \multirow[b]{2}{*}{ BA } & \multirow[b]{2}{*}{$p$ value (FWE) } & \multirow[t]{2}{*}{$t$ value } & \multicolumn{3}{|c|}{ Coordinates (MNI) } \\
\hline & & & & & $x$ & $Y$ & $z$ \\
\hline \multirow[t]{3}{*}{ Frontal cortex } & R. paracingulate & 10 & 0.0111 & 3.8 & 14 & 50 & 8 \\
\hline & L. Broca's area & 44 & 0.0107 & 4.12 & -42 & 12 & 16 \\
\hline & L. frontal pole & 11 & 0.0397 & 2.79 & 30 & 42 & -12 \\
\hline \multirow{4}{*}{ Sensorimotor areas } & R. primary somatosensory Cortex & 3a & 0.0053 & 4.24 & 26 & -32 & 50 \\
\hline & L. primary somatosensory Cortex & $3 b$ & 0.0048 & 4.45 & -20 & -40 & 52 \\
\hline & R. supplementary motor area & 6 & 0.0111 & 3.34 & 14 & 50 & 6 \\
\hline & R. supplementary motor area & 6 & 0.0294 & 3.20 & 14 & -2 & 44 \\
\hline \multirow[t]{8}{*}{ Occipital cortex } & R. visual cortex V5 & 37 & 0.0009 & 5.03 & 54 & -60 & 8 \\
\hline & R. visual cortex V2 & 18 & 0.0012 & 4.64 & 8 & -78 & 30 \\
\hline & & & 0.0013 & 4.16 & 18 & -58 & -4 \\
\hline & L. occipital pole & 18 & 0.0041 & 4.2 & -26 & -98 & 24 \\
\hline & R. lateral occipital cortex & 19 & 0.0018 & 4.55 & 36 & -80 & 12 \\
\hline & L. lateral occipital cortex & 37 & 0.0023 & 4.15 & -48 & -64 & -4 \\
\hline & R. lingual gyrus & 37 & 0.0031 & 4.34 & 22 & -46 & -10 \\
\hline & & 18 & 0.0012 & 4.26 & 10 & -62 & 0 \\
\hline Temporal cortex & R. middle temporal gyrus & 21 & 0.0012 & 4.41 & 58 & -48 & 0 \\
\hline Cerebellum & R. cerebellum I-IV & & 0.0022 & 4.08 & 2 & -48 & -18 \\
\hline \multirow[t]{4}{*}{ Subcortical } & R. thalamus & & 0.0046 & 3.15 & 8 & -18 & 2 \\
\hline & R. caudate & & 0.0167 & 3.4 & 16 & 20 & 10 \\
\hline & L. caudate & & 0.0139 & 2.7 & -12 & 18 & 0 \\
\hline & R. amygdala & & 0.0086 & 3.28 & 32 & -8 & -12 \\
\hline
\end{tabular}

Note. The $t$ values, $p$ values, and MNI coordinates indicate peak voxels within the clusters. BA, Brodmann area; FWE: family-wise error rate; MNI: Montreal Neurological Institute.

cognitive performance, whereas higher doses from $3 \mathrm{mg}$ do induce impairments (Legangneux et al., 2000). Alternatively, higher L-dopa doses may have resulted in enhanced $\mathrm{N}$-back performance, perhaps represented by increasing response speed, without decreasing accuracy (Eckart et al., 2014).

A clear limitation of the present study is that it was designed as a proof-of-principle study to explore the potential effects D1 stimulation on working memory-related brain activation, operationalised by combined haloperidol/L-dopa administration. Therefore the study did not include all treatment conditions for a full factorial design and, thus, the contribution of L-dopa and haloperidol alone, as well as the interaction between treatments, could not be determined. Nonetheless, within the context and current aim of understanding combined treatment effects, we were able to confirm dopamine enhancing effects as measured with fMRI as a highly sensitive measure to such changes.

The binding profile of haloperidol to presynaptic and postsynaptic receptors potentially complicates the interpretation of the results and, thus, needs to be considered. Indeed, this issue is relevant to all studies that administer dopaminergic stimulants, D2 agonists or D2 antagonists. Haloperidol can bind to both presynaptic and postsynaptic D2 receptors. The D2 presynaptic receptors are autoreceptors and binding to the presynaptic receptor causes an increase in extracellular dopamine levels (Lidsky \& Banerjee, 1993). Nonetheless, its postsynaptic D2 receptor blocking potential causes the desired reduction in D2 receptor mediated dopamine action, in line with our interpretation. For our particular study, the argument can be considered that the 


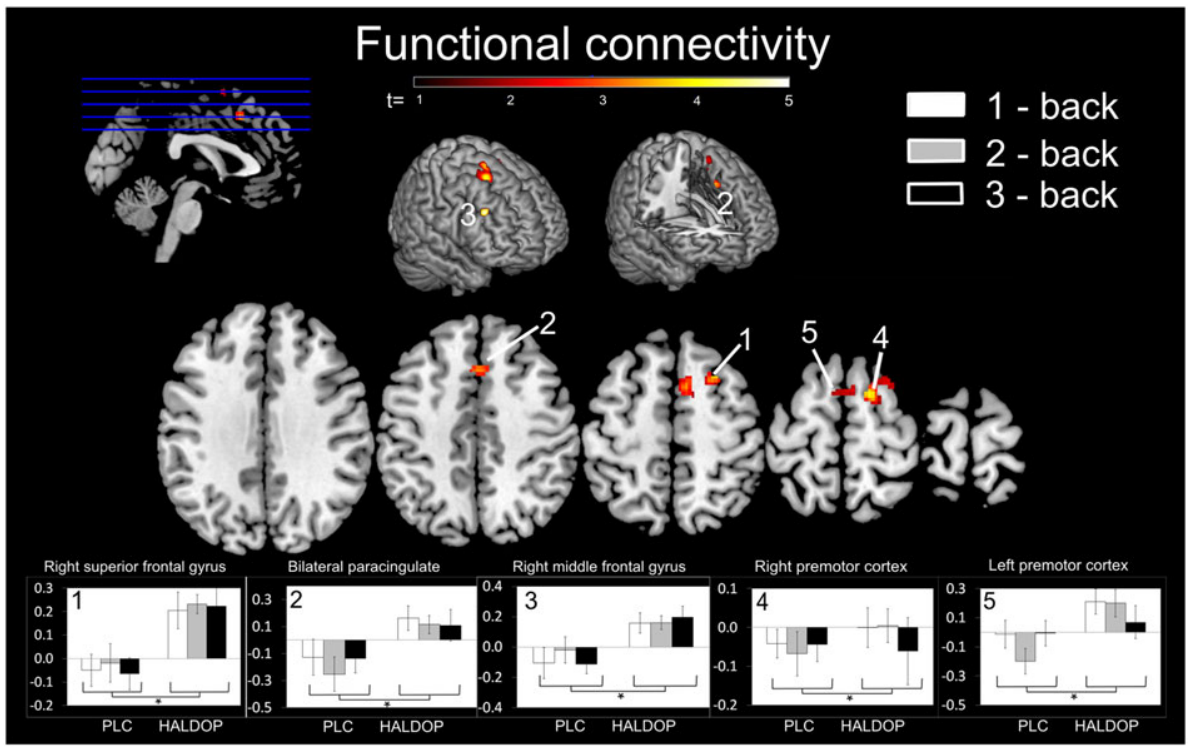

FIGURE 4 An increase in functional connectivity between the right dorsolateral prefrontal cortex and frontal/sensorimotor areas was observed after haloperidol/L-dopa treatment during N-back task performance (1-, 2-, and 3-back vs. 0-back; $n$ = 12). HAL/DOP: haloperidol/L-dopa treatment; PLC: placebo

TABLE 4 Brain areas in which haloperidol/L-dopa produces higher correlations with task dependent dorsolateral prefrontal cortex activation compared with placebo

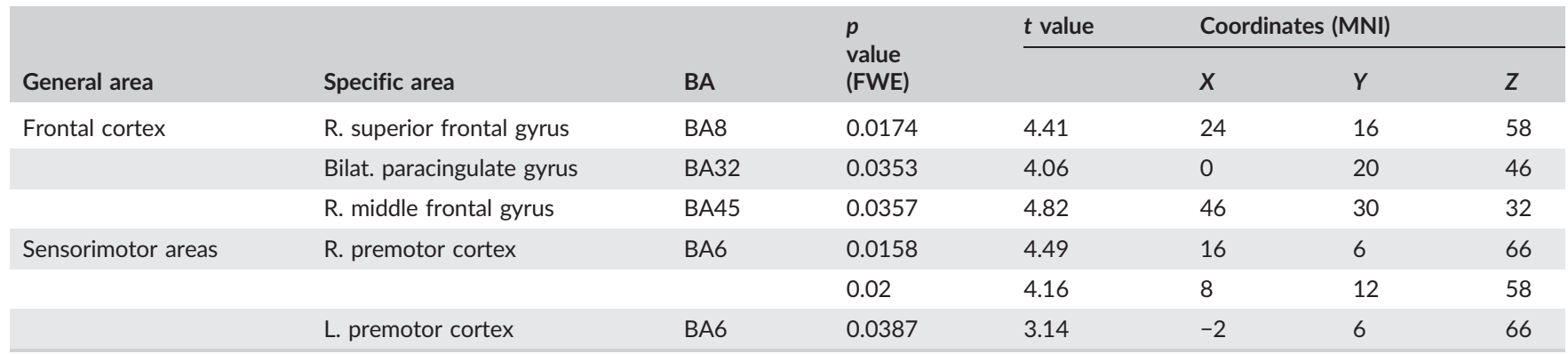

Note. The $t$ values, $p$ values, and MNI coordinates indicate peak voxels within the clusters. BA, Brodmann area; FWE: family-wise error rate; MNI: Montreal Neurological Institute.

presynaptic effects are less of an issue as the impact of levodopa is to increase dopamine release. In addition, the binding of haloperidol to both presynaptic and postsynaptic receptors is something that also occurs with dopamine itself. Therefore, the intended effect of blocking D2 activation is achieved, whether this is presynaptically/postsynaptically or both.

A final limitation concerns the number of included participants in this study. As data from only 12 participants were analysed, any strong conclusions cannot be drawn from these data. For example, post hoc calculations to determine achieved power showed that the main drug effect on reaction time could only be determined with power of 0.40 . Nonetheless, we observed significant drug effects on brain activation that are in accordance with previous studies using dopamine manipulations confirming effective manipulations.

\section{5 | CONCLUSION}

The precise implications for disorders with working memory impairment such as schizophrenia are complicated by the fact that
[18F]-DOPA imaging studies have consistently demonstrated increased dopamine synthesis capacity (e.g., Howes et al., 2007). This would argue against the use of L-dopa, which would further elevate presynaptic dopamine function in the striatum. Studies in experimental animals combined with our findings of increased functional connectivity within an $\mathrm{N}$-back related network point towards extrastriatal action of L-dopa combined with haloperidol as an important mechanism to improve cognitive performance, thus predicting utility for drugs that favour modulation of cortical dopamine projections. Therefore, in conclusion, the present study provides initial support for the combination of an indirect dopamine agonist with a dopamine antagonist having the required effects that resemble those of increased frontal catecholamine activity, but any strong conclusion should await replication in a larger study, including a full factorial design and higher doses of L-dopa.

\section{ACKNOWLEDGEMENT}

The authors would like to acknowledge Prof. Dr. Shitij Kapur for discussion. 


\section{CONFLICTS OF INTEREST}

No conflicts of interest have bene declared.

\section{SOURCE OF FUNDING}

This research received no specific grant from any funding agency in the public, commercial, or not-for-profit sectors.

\section{AUTHOR CONTRIBUTIONS}

Peter van Ruitenbeek has collected the data, designed and performed the analysis, and drafted the manuscript.

Dennis Hernaus has assisted in data collection, corrected, and revised the manuscript.

Mitul Ashok Mehta designed the study and analysis plan, corrected, and revised the manuscript.

\section{ORCID}

Peter van Ruitenbeek (D) http://orcid.org/0000-0002-3802-6551

\section{REFERENCES}

Abi-Dargham, A. (2003). Probing cortical dopamine function in schizophrenia: What can D1 receptors tell us? World Psychiatry, 2(3), 166-171.

Abi-Dargham, A., Martinez, D., Mawlawi, O., Simpson, N., Hwang, D. R., Slifstein, M., ... Laruelle, M. (2000). Measurement of striatal and extrastriatal dopamine D1 receptor binding potential with [11C] NNC 112 in humans: Validation and reproducibility. Journal of Cerebral Blood Flow and Metabolism, 20(2), 225-243. https://doi.org/10.1097/ 00004647-200002000-00003

Abi-Dargham, A., Mawlawi, O., Lombardo, I., Gil, R., Martinez, D., Huang, Y., ... Laruelle, M. (2002). Prefrontal dopamine D1 receptors and working memory in schizophrenia. The Journal of Neuroscience, 22(9), 3708-3719. 20026302

Akaike, A., Ohno, Y., Sasa, M., \& Takaori, S. (1987). Excitatory and inhibitory effects of dopamine on neuronal activity of the caudate nucleus neurons in vitro. Brain Research, 418(2), 262-272.

Arnsten, A. F., Girgis, R. R., Gray, D. L., \& Mailman, R. B. (2016). Novel dopamine therapeutics for cognitive deficits in schizophrenia. Biological Psychiatry, 81, 67-77. https://doi.org/10.1016/j. biopsych.2015.12.028

Bertolino, A., Sciota, D., Brudaglio, F., Altamura, M., Blasi, G., Bellomo, A., ... Nardini, M. (2003). Working memory deficits and levels of $\mathrm{N}$ acetylaspartate in patients with schizophreniform disorder. The American Journal of Psychiatry, 160(3), 483-489. https://doi.org/ 10.1176/appi.ajp.160.3.483

Blanchet, P. J., Fang, J., Gillespie, M., Sabounjian, L., Locke, K. W., Gammans, R., ... Chase, T. N. (1998). Effects of the full dopamine D1 receptor agonist dihydrexidine in Parkinson's disease. Clinical Neuropharmacology, 21(6), 339-343.

Bond, A., \& Lader, M. (1974). The use of analogue scales in rating subjective feelings. British Journal of Medical Psychology, 47, 211-218.

Brassen, S., Tost, H., Hoehn, F., Weber-Fahr, W., Klein, S., \& Braus, D. F. (2003). Haloperidol challenge in healthy male humans: A functional magnetic resonance imaging study. Neuroscience Letters, 340(3), 193-196. doi: S0304394003001046 [pii]

Breitenstein, C., Floel, A., Korsukewitz, C., Wailke, S., Bushuven, S., \& Knecht, S. (2006). A shift of paradigm: From noradrenergic to dopaminergic modulation of learning? Journal of the Neurological Sciences, 248(1-2), 42-47. https://doi.org/10.1016/j.jns.2006.05.012

Callicott, J. H., Bertolino, A., Mattay, V. S., Langheim, F. J., Duyn, J., Coppola, R., ... Weinberger, D. R. (2000). Physiological dysfunction of the dorsolateral prefrontal cortex in schizophrenia revisited. Cerebral Cortex, 10(11), 1078-1092.
Castner, S. A., \& Goldman-Rakic, P. S. (2004). Enhancement of working memory in aged monkeys by a sensitizing regimen of dopamine D1 receptor stimulation. The Journal of Neuroscience, 24(6), 1446-1450. https://doi.org/10.1523/JNEUROSCI.3987-03.200424/6/1446 [pii]

Chamberlain, S. R., Hampshire, A., Muller, U., Rubia, K., Del Campo, N., Craig, K., ... Sahakian, B. J. (2009). Atomoxetine modulates right inferior frontal activation during inhibitory control: A pharmacological functional magnetic resonance imaging study. Biological Psychiatry, 65(7), 550-555. https://doi.org/10.1016/j.biopsych.2008.10.014

Cole, D. M., Oei, N. Y., Soeter, R. P., Both, S., van Gerven, J. M., Rombouts, S. A., \& Beckmann, C. F. (2013). Dopamine-dependent architecture of cortico-subcortical network connectivity. Cerebral Cortex, 23(7), 1509-1516. https://doi.org/10.1093/cercor/bhs136

Contin, M., \& Martinelli, P. (2010). Pharmacokinetics of levodopa. Journal of Neurology, 257(Suppl 2), S253-S261. https://doi.org/10.1007/ s00415-010-5728-8

Cools, R., \& D'Esposito, M. (2011). Inverted-U-shaped dopamine actions on human working memory and cognitive control. Biological Psychiatry, 69(12), e113-e125. https://doi.org/10.1016/j.biopsych.2011.03.028

Dumas, J. A., Filippi, C. G., Newhouse, P. A., \& Naylor, M. R. (2017). Dopaminergic contributions to working memory-related brain activation in postmenopausal women. Menopause, 24(2), 163-170. https://doi.org/ 10.1097/GME.0000000000000738

Eckart, C., Fuentemilla, L., Bauch, E. M., \& Bunzeck, N. (2014). Dopaminergic stimulation facilitates working memory and differentially affects prefrontal low theta oscillations. Neurolmage, 94, 185-192. https:// doi.org/10.1016/j.neuroimage.2014.03.011

Fioravanti, M., Bianchi, V., \& Cinti, M. E. (2012). Cognitive deficits in schizophrenia: An updated metanalysis of the scientific evidence. BMC Psychiatry, 12, 64. https://doi.org/10.1186/1471-244X-12-64

Floel, A., Garraux, G., Xu, B., Breitenstein, C., Knecht, S., Herscovitch, P., \& Cohen, L. G. (2008). Levodopa increases memory encoding and dopamine release in the striatum in the elderly. Neurobiology of Aging, 29(2), 267-279. https://doi.org/10.1016/j.neurobiolaging.2006.10.009

Furey, M. L., Pietrini, P., Alexander, G. E., Schapiro, M. B., \& Horwitz, B. (2000). Cholinergic enhancement improves performance on working memory by modulating the functional activity in distinct brain regions: A positron emission tomography regional cerebral blood flow study in healthy humans. Brain Research Bulletin, 51(3), 213-218.

Gass, N., Schwarz, A. J., Sartorius, A., Cleppien, D., Zheng, L., Schenker, E., ... Weber-Fahr, W. (2013). Haloperidol modulates midbrain-prefrontal functional connectivity in the rat brain. European Neuropsychopharmacology, 23(10), 1310-1319. https://doi.org/ 10.1016/j.euroneuro.2012.10.013

George, M. S., Molnar, C. E., Grenesko, E. L., Anderson, B., Mu, Q., Johnson, K., ... Mailman, R. B. (2007). A single $20 \mathrm{mg}$ dose of dihydrexidine (DAR-0100), a full dopamine D1 agonist, is safe and tolerated in patients with schizophrenia. Schizophrenia Research, 93(1-3), 42-50. doi: S0920-9964(07)00119-3 [pii] https://doi.org/10.1016/j. schres.2007.03.011

Gibbs, S. E., \& D'Esposito, M. (2005a). A functional MRI study of the effects of bromocriptine, a dopamine receptor agonist, on component processes of working memory. Psychopharmacology, 180(4), 644-653. https://doi.org/10.1007/s00213-005-0077-5

Gibbs, S. E., \& D'Esposito, M. (2005b). Individual capacity differences predict working memory performance and prefrontal activity following dopamine receptor stimulation. Cognitive, Affective, \& Behavioral Neuroscience, 5(2), 212-221.

Girgis, R. R., Van Snellenberg, J. X., Glass, A., Kegeles, L. S., Thompson, J. L., Wall, M., ... Lieberman, J. A. (2016). A proof-of-concept, randomized controlled trial of DAR-0100A, a dopamine-1 receptor agonist, for cognitive enhancement in schizophrenia. Journal of Psychopharmacology, 30(5), 428-435. https://doi.org/10.1177/0269881116636120

Goldberg, T. E., Goldman, R. S., Burdick, K. E., Malhotra, A. K., Lencz, T., Patel, R. C., ... Robinson, D. G. (2007). Cognitive improvement after treatment with second-generation antipsychotic medications in first- 
episode schizophrenia: Is it a practice effect? Archives of General Psychiatry, 64(10), 1115-1122. 64/10/1115 [pii] https://doi.org/10.1001/ archpsyc.64.10.1115

Goldman-Rakic, P. S., Castner, S. A., Svensson, T. H., Siever, L. J., \& Williams, G. V. (2004). Targeting the dopamine D1 receptor in schizophrenia: Insights for cognitive dysfunction. Psychopharmacology, 174(1), 3-16. https://doi.org/10.1007/s00213-004-1793-y

Goozee, R., Reinders, A. A., Handley, R., Marques, T., Taylor, H., O'Daly, O., ... Dazzan, P. (2016). Effects of aripiprazole and haloperidol on neural activation during the $\mathrm{n}$-back in healthy individuals: A functional MRI study. Schizophrenia Research, 173(3), 174-181. https://doi.org/ 10.1016/j.schres.2015.02.023

Green, M. F., Kern, R. S., Braff, D. L., \& Mintz, J. (2000). Neurocognitive deficits and functional outcome in schizophrenia: Are we measuring the "right stuff"? Schizophrenia Bulletin, 26(1), 119-136.

Grill-Spector, K., \& Malach, R. (2004). The human visual cortex. Annual Review of Neuroscience, 27, 649-677. https://doi.org/10.1146/ annurev.neuro.27.070203.144220

Handley, R., Zelaya, F. O., Reinders, A. A., Marques, T. R., Mehta, M. A., O'Gorman, R., ... Dazzan, P. (2013). Acute effects of single-dose aripiprazole and haloperidol on resting cerebral blood flow (rCBF) in the human brain. Human Brain Mapping, 34(2), 272-282. https://doi. org/10.1002/hbm.21436

Hawkins, P. C. T., Wood, T. C., Vernon, A. C., Bertolino, A., Sambataro, F., Dukart, J., ... Mehta, M. A. (2018). An investigation of regional cerebral blood flow and tissue structure changes after acute administration of antipsychotics in healthy male volunteers. Human Brain Mapping, 39(1), 319-331. https://doi.org/10.1002/hbm.23844

Hernaus, D., Casales Santa, M. M., Offermann, J. S., \& Van Amelsvoort, T. (2017). Noradrenaline transporter blockade increases fronto-parietal functional connectivity relevant for working memory. European Neuropsychopharmacology, 27(4), 399-410. https://doi.org/10.1016/j. euroneuro.2017.02.004

Hershey, T., Black, K. J., Carl, J. L., McGee-Minnich, L., Snyder, A. Z., \& Perlmutter, J. S. (2003). Long term treatment and disease severity change brain responses to levodopa in Parkinson's disease. Journal of Neurology, Neurosurgery, and Psychiatry, 74(7), 844-851.

Howes, O. D., Montgomery, A. J., Asselin, M. C., Murray, R. M., Grasby, P. M., \& McGuire, P. K. (2007). Molecular imaging studies of the striatal dopaminergic system in psychosis and predictions for the prodromal phase of psychosis. The British Journal of Psychiatry. Supplement, 51, s13-s18. https://doi.org/10.1192/bjp.191.51.s13

Jenkinson, M., Beckmann, C. F., Behrens, T. E., Woolrich, M. W., \& Smith, S. M. (2012). Fsl. Neurolmage, 62(2), 782-790. https://doi.org/ 10.1016/j.neuroimage.2011.09.015

Kimberg, D. Y., Aguirre, G. K., Lease, J., \& D'Esposito, M. (2001). Cortical effects of bromocriptine, a D-2 dopamine receptor agonist, in human subjects, revealed by fMRI. Human Brain Mapping, 12(4), 246-257.

Knecht, S., Breitenstein, C., Bushuven, S., Wailke, S., Kamping, S., Floel, A., ... Ringelstein, E. B. (2004). Levodopa: Faster and better word learning in normal humans. Annals of Neurology, 56(1), 20-26. https://doi.org/ 10.1002/ana.20125

Kudo, S., \& Ishizaki, T. (1999). Pharmacokinetics of haloperidol: An update. Clinical Pharmacokinetics, 37(6), 435-456. https://doi.org/10.2165/ 00003088-199937060-00001

Legangneux, E., McEwen, J., Wesnes, K. A., Bergougnan, L., Miget, N., Canal, M., ... Rosenzweig, P. (2000). The acute effects of amisulpride (50 $\mathrm{mg}$ and $200 \mathrm{mg}$ ) and haloperidol $(2 \mathrm{mg}$ ) on cognitive function in healthy elderly volunteers. Journal of Psychopharmacology, 14(2), 164-171.

Lidsky, T. I., \& Banerjee, S. P. (1993). Acute administration of haloperidol enhances dopaminergic transmission. The Journal of Pharmacology and Experimental Therapeutics, 265(3), 1193-1198.

Luijten, M., Veltman, D. J., Hester, R., Smits, M., Nijs, I. M., Pepplinkhuizen, L., \& Franken, I. H. (2013). The role of dopamine in inhibitory control in smokers and non-smokers: A pharmacological fMRI study. European Neuropsychopharmacology, 23(10), 1247-1256. https://doi.org/ 10.1016/j.euroneuro.2012.10.017

Marder, S. R. (2006). Drug initiatives to improve cognitive function. The Journal of Clinical Psychiatry, 67(Suppl 9), 31-35. discussion 36-42

Mattay, V. S., Callicott, J. H., Bertolino, A., Heaton, I., Frank, J. A., Coppola, R., ... Weinberger, D. R. (2000). Effects of dextroamphetamine on cognitive performance and cortical activation. Neurolmage, 12(3), 268-275. https://doi.org/10.1006/nimg.2000.0610

McLaren, D. G., Ries, M. L., Xu, G., \& Johnson, S. C. (2012). A generalized form of context-dependent psychophysiological interactions (gPPI): A comparison to standard approaches. Neurolmage, 61(4), 1277-1286. https://doi.org/10.1016/j.neuroimage.2012.03.068

McLean, S. L., Idris, N. F., Woolley, M. L., \& Neill, J. C. (2009). D(1)-like receptor activation improves $\mathrm{PCP}$-induced cognitive deficits in animal models: Implications for mechanisms of improved cognitive function in schizophrenia. European Neuropsychopharmacology, 19(6), 440-450. doi: S0924-977X(09)00030-3 [pii] https://doi.org/10.1016/j. euroneuro.2009.01.009

Meyer-Lindenberg, A., Poline, J. B., Kohn, P. D., Holt, J. L., Egan, M. F., Weinberger, D. R., \& Berman, K. F. (2001). Evidence for abnormal cortical functional connectivity during working memory in schizophrenia. The American Journal of Psychiatry, 158(11), 1809-1817. https:// doi.org/10.1176/appi.ajp.158.11.1809

Mu, Q., Johnson, K., Morgan, P. S., Grenesko, E. L., Molnar, C. E., Anderson, B., ... George, M. S. (2007). A single $20 \mathrm{mg}$ dose of the full D1 dopamine agonist dihydrexidine (DAR-0100) increases prefrontal perfusion in schizophrenia. Schizophrenia Research, 94(1-3), 332-341. doi: S09209964(07)00128-4 [pii] https://doi.org/10.1016/j.schres.2007.03.033

Nielsen, R. E., Levander, S., Kjaersdam Telleus, G., Jensen, S. O., Ostergaard Christensen, T., \& Leucht, S. (2015). Second-generation antipsychotic effect on cognition in patients with schizophrenia-A meta-analysis of randomized clinical trials. Acta Psychiatrica Scandinavica, 131(3), 185-196. https://doi.org/10.1111/acps.12374

Owen, A. M., McMillan, K. M., Laird, A. R., \& Bullmore, E. (2005). N-back working memory paradigm: A meta-analysis of normative functional neuroimaging studies. Human Brain Mapping, 25(1), 46-59. https:// doi.org/10.1002/hbm.20131

Rieckmann, A., Karlsson, S., Fischer, H., \& Backman, L. (2012). Increased bilateral frontal connectivity during working memory in young adults under the influence of a dopamine D1 receptor antagonist. The Journal of Neuroscience, 32(48), 17067-17072. https://doi.org/10.1523/ JNEUROSCI.1431-12.2012

Rosell, D. R., Zaluda, L. C., McClure, M. M., Perez-Rodriguez, M. M., Strike, K. S., Barch, D. M., ... Siever, L. J. (2015). Effects of the D1 dopamine receptor agonist dihydrexidine (DAR-0100A) on working memory in schizotypal personality disorder. Neuropsychopharmacology, 40(2), 446-453. https://doi.org/10.1038/npp.2014.192

Rosen, H., Flemenbaum, A., \& Slater, V. L. (1986). Clinical trial of carbidopaL-dopa combination for cocaine abuse. The American Journal of Psychiatry, 143(11), 1493.

Saha, S., Chant, D., \& McGrath, J. (2007). A systematic review of mortality in schizophrenia: Is the differential mortality gap worsening over time? Archives of General Psychiatry, 64(10), 1123-1131. https://doi.org/ 10.1001/archpsyc.64.10.1123

Sawaguchi, T., \& Goldman-Rakic, P. S. (1991). D1 dopamine receptors in prefrontal cortex: Involvement in working memory. Science, 251(4996), 947-950.

Seamans, J. K., Gorelova, N., Durstewitz, D., \& Yang, C. R. (2001). Bidirectional dopamine modulation of GABAergic inhibition in prefrontal cortical pyramidal neurons. The Journal of Neuroscience, 21(10), 3628-3638. doi: 21/10/3628 [pii]

Shine, J., van den Brink, R., Hernaus, D., Nieuwenhuis, S., \& Poldrack, R. (2017). Catecholaminergic manipulation alters dynamic network topology across behavioral states. bioRxiv. doi: https://doi.org/10.1101/169102 
Slifstein, M., Suckow, R. F., Javitch, J. A., Cooper, T., Lieberman, J., \& AbiDargham, A. (2011). Characterization of in vivo pharmacokinetic properties of the dopamine D1 receptor agonist DAR-0100A in nonhuman primates using PET with [11C] NNC112 and [11C] raclopride. Journal of Cerebral Blood Flow and Metabolism, 31(1), 293-304. https://doi. org/10.1038/jcbfm.2010.91

SPSS inc. (2009) (Version 18). Chicago: PASW Statistics for Windows.

Symmonds, M., Wright, N. D., Fagan, E., \& Dolan, R. J. (2013). Assaying the effect of levodopa on the evaluation of risk in healthy humans. PLoS One, 8(7), e68177. https://doi.org/10.1371/journal. pone.0068177

Thompson, J. L., Rosell, D. R., Slifstein, M., Girgis, R. R., Xu, X., Ehrlich, Y., ... Siever, L. J. (2014). Prefrontal dopamine D1 receptors and working memory in schizotypal personality disorder: A PET study with [(1)(1) C]NNC112. Psychopharmacology, 231(21), 4231-4240. https://doi. org/10.1007/s00213-014-3566-6

van den Brink, R. L., Pfeffer, T., Warren, C. M., Murphy, P. R., Tona, K. D., van der Wee, N. J., ... Nieuwenhuis, S. (2016). Catecholaminergic neuromodulation shapes intrinsic MRI functional connectivity in the human brain. The Journal of Neuroscience, 36(30), 7865-7876. https://doi.org/10.1523/JNEUROSCI.0744-16.2016

Vytlacil, J., Gibbs, S., Chen, A., \& D'Esposito, M. (2009). Dopamine levels modulate the effects of attention on activation patterns in visual association cortex. Neurolmage, 47(S1), S39-S41.

Winkler, A. M., Ridgway, G. R., Webster, M. A., Smith, S. M., \& Nichols, T. E. (2014). Permutation inference for the general linear model. Neurolmage, 92, 381-397. https://doi.org/10.1016/j. neuroimage.2014.01.060

Wittmann, B. C., \& D'Esposito, M. (2015). Levodopa administration modulates striatal processing of punishment-associated items in healthy participants. Psychopharmacology, 232(1), 135-144. https://doi.org/ 10.1007/s00213-014-3646-7

World-Medical-Association (Producer). (1964, 1996, 2008, 2013). World Medical Association Declaration of Helsinki: Ethical principles for medical research involving human subjects. Retrieved from http://www. wma.net/en/30publications/10policies/b3/index.html

Yoon, J. H., Curtis, C. E., \& D'Esposito, M. (2006). Differential effects of distraction during working memory on delay-period activity in the prefrontal cortex and the visual association cortex. Neurolmage, 29(4), 1117-1126. doi: S1053-8119(05)00648-8 [pii] https://doi.org/ 10.1016/j.neuroimage.2005.08.024

How to cite this article: Van Ruitenbeek P, Hernaus D, Mehta MA. A proof-of-principle study of the effect of combined haloperidol and levodopa administration on working memoryrelated brain activation in humans. Hum Psychopharmacol Clin Exp. 2018;33:e2675. https://doi.org/10.1002/hup.2675 